\title{
The Effect of Changing Proximate Determinants on Fertility Levels among Urban Poor Women in Kenya: Evidence from Nairobi's Informal Settlements, 2000-2012
}

\author{
Marylene Wamukoya ${ }^{1}$, Donatien Beguy ${ }^{1}$, Kanyiva Muindi ${ }^{1}$, Joyce Mumah ${ }^{1}$, and Blessing \\ Mberu $^{1}$ \\ ${ }^{1}$ African Population and Health Research Center, \\ P.O. Box 10787-00100, Nairobi \\ Kenya \\ mwamukoya@aphrc.org.
}

\begin{abstract}
Slum dwellers constitute an increasing share of urban populations in sub-Saharan Africa. This paper examines changes in proximate determinants of fertility in slums in Nairobi, Kenya between 2000 and 2012. We used data from the Nairobi Cross-sectional Slum Surveys (NCSS) conducted in in all Nairobi's informal settlements, among 3,256 women aged I5-49 in 2000 and 4,240 aged I2-49 in 20 I 2 . We employed Stover's revised proximate determinants of fertility framework to assess the relative contribution of contraception, marriage, sterility and postpartum insusceptibility to the fertility levels between 2000 and 20I2. There has been a change in the influence of the proximate determinants in Nairobi's slums. Marriage as measured by recent sexual activity had the largest inhibiting effect in 2000, whereas contraception had the largest effect in 2012. Findings suggest the need to sustain and/or strengthen FP/SRH initiatives that emphasize contraceptive use among women in urban slums in Kenya.
\end{abstract}

\section{Résumé}

Les habitants des bidonvilles constituent une part croissante des populations urbaines en Afrique subsaharienne. Cet article examine les changements dans les déterminants immédiats de la fécondité dans les bidonvilles de Nairobi, au Kenya entre 2000 et 2012. Nous avons utilisé les données des enquêtes sur les bidonvilles de Nairobi transversales (SNSC) menée dans des quartiers informels de Nairobi tous, entre 3.256 femmes de 15-49 ans en 2000 et 4240 ans 12-49 en 20I2. Nous avons utilisé les déterminants immédiats révisés Stover du cadre de la fertilité pour évaluer la contribution relative de la contraception, le mariage, la stérilité et infécondité post-partum aux niveaux de fécondité entre 2000 et 2012. II y a eu un changement dans l'influence des déterminants immédiats dans les bidonvilles de Nairobi. Mariage tel que mesuré par l'activité sexuelle récente a eu le plus grand effet inhibiteur en 2000 , alors que la contraception a eu l'effet le plus important en 20/2. Les résultats suggèrent la nécessité de maintenir et / ou renforcer les initiatives FP / SRH qui mettent l'accent sur l'utilisation des contraceptifs chez les femmes dans les bidonvilles au Kenya.

\section{Introduction and Background}

Sub-Saharan Africa (SSA) is the world's most rapidly urbanizing region, with most of this growth concentrated in informal settlements or slums (Agbola and Agunbiade, 2009). It is projected that by 2030, seventy percent of the world's population will reside in a city with an urban profile (Chan, 20I0). At the current annual growth rate of about 2.3 percent per year (UN, 2004), it is estimated that the urban population in SSA will grow by over 300 million new residents by 2030 (Kessides, 2005).

Unlike in other developing regions, high natural increase is the main driver of the rapid urban population growth in SSA, contributing to about 75 percent of its urban growth. Only 25 percent is driven by rural-urban migration (Chen et al., 1998). This high natural increase is mostly attributed to the relatively high fertility levels, which are far above replacement levels in most SSA countries. In the vast majority of countries in this region, women have on average more than five children during their reproductive life. In addition, the increase in the relatively high proportions of people of reproductive age in urban populations results in a high number of births in urban settings in SSA. This is particularly true since less developed countries have more young people of reproductive age (Bremner et al., 2009, 
UN, 2009). Given the role of natural increase in driving urban growth, it is important to have a better understanding of the fertility patterns and its determinants among urban populations. In particular, reproductive behaviour of slum dwellers who constitute a huge and increasing share of urban population in this region needs more attention as it will help address increasing "slumization" of cities in SSA. Evidence show that much of the high fertility among the urban poor is either mistimed or unwanted in many SSA countries (Ezeh et al., 2010).

Indeed, about two thirds of the urban population in SSA resides in slums and this is by far the highest proportion among all developing regions in the world (UN-Habitat, 2003b, UN-Habitat, 2003c). Cities and in particular informal settlements, concentrate risks and health hazards leading to challenges such as poor water and sanitation infrastructure, insecurity, inadequate and overcrowded housing and lack of access to basic human needs such as schooling and health services (Kyobutungi et al., 2008, Chan, 2010, Agbola and Agunbiade, 2009, UN-Habitat, 2003b). Despite living in urban settings, indicators among slum populations usually have more in common with rural areas than with indicators among non-slum urban residents, particularly among first-generation urban slum residents (Ezeh et al., 2010). Poverty has now become a characteristic of cities, rather than scattered rural areas (Chan, 20l0).

It is apparent that lives of slum dwellers will increasingly determine SSA's demographic and socioeconomic prospects if these patterns and trends continue unchecked. Yet despite the fact that the poor constitute an increasing share of the urban populations, not much attention has been given to their reproductive behavior. More often than not, their situation is hidden in urban indicators, making it difficult to identify specific evidence that could inform the design and implementation of programs/actions geared towards improving their living conditions (Rossier et al., 2014). In this paper, we take advantage of unique data collected in all slums in Nairobi city, Kenya in 2000 and 2012, to examine changes in prevailing fertility levels by looking at changes in Bongaarts' proximate determinants of fertility (Johnson et al., 20II) in Nairobi slums and compare these with national estimates from the 2008-2009 Kenya Demographic and Health Survey (KDHS). Specifically, we investigate the contribution of the proximate determinants to fertility levels and whether changes in the determinants were associated with changes in fertility levels among women aged 15-49 years living in Nairobi's informal settlements. To determine whether the trends are similar to those of urban Kenya and Nairobi as a whole based on national surveys, we contrast these women against similarly aged women in Nairobi, rural Kenya and Kenya as a whole in 2008-2009. We examine trends in age at first marriage and at first sexual experience and prevalence of contraceptive use. Further, we use Stover's revised (Bongaarts and Potter, 1983) proximate determinants of fertility framework to estimate and compare the contribution of marriage, contraception, insusceptibility and sterility to the fertility levels in Nairobi's informal settlements. We do not consider the contribution of abortion because there was insufficient data to measure its effect on fertility.

Kenya typifies the escalating urban crisis in SSA, with Nairobi its capital city being home to more than 100 informal and squatter settlements (UN-Habitat, 2003a). These slums have the worst profiles among similar settlements in other cities and countries in SSA as they are more dense, extremely unsanitary and exceedingly insecure (UN-Habitat, 2003a). Urban poor are faced with poor reproductive health outcomes compared to urban non-poor residents. Nairobi's urban poor are more likely to initiate sexual activity early and have more sexual partners partly because of the environment in which they live which contributes to socialization of children into sexual activity (Zulu et al., 2002). The conditions in slums are characterized by economic hardships, open practice of prostitution and crowded households in which sexually active parents/parental figures have very little privacy during sexual activities (Zulu et al., 2002).

\section{Proximate Determinants of Fertility Framework}

Fertility levels and changes in most populations can be explained by the Bongaarts' model of proximate determinants, which are behavioral mechanisms that have the potential to lower theoretical or biological fertility maximums for a given population (Johnson et al., 20II). Bongaarts defined four proximate determinants in the original model (Bongaarts and Potter, 1983). These included marriage (which exposed women to the risk of pregnancy); postpartum amenorrhea (the duration between childbirth and ovulation, which can be significantly extended depending on the intensity and duration of breastfeeding); contraceptive use; and induced abortion whose effects are realized after conception (Johnson et al., 20II, Short, 1993). Bongaarts later added a fifth determinant, that is, pathological sterility, which by definition prevents conception. Five indices were developed that together explain fertility: the index of marriage, the index of contraception, the index of post-partum insusceptibility, the index of sterility and the index of abortion (Bongaarts et al., 1984, Stover, 1998). 
Bongaarts' model has come under criticisms since its development in the 1970s. The model assumed that all fertility could be explained by the proximate determinants, without the inclusion of various social, economic and cultural factors. However in 2007, Baschieri and Hinde found unexplained variations in fertility that could be explained by social, economic and cultural factors (Baschieri and Hinde, 2007). In addition, Bongaarts' model assumes that marriage marks the beginning of sexual activity and therefore the beginning of a woman's exposure to the risk of pregnancy (UNFPA, 20I4). There has been an increase in the prevalence of pre-marital sexual activity in many different populations and childbearing out of wedlock is now more common, particularly in countries where consensual unions are generally accepted (UN, 20I3). Moreover, the social stigma surrounding out-of-wedlock births has been waning (Gage and Meekers, 1994, UN, 2013).

In the late 1990s, the model was revised by John Stover (1998) to account for some of these limitations, particularly those surrounding the best marker for the onset of exposure to conception. In the revised model, the index of marriage is approximated by the proportion of women aged 1549 that are sexually active whereas it was previously estimated by determining the proportion of women of reproductive age that are married. The original index of contraception assessed the prevalence of contraceptive use among married women aged I5-49 years, while the revised model uses the prevalence of contraceptive use among sexually active women of reproductive age (Stover, 1998). Despite these limitations, Bongaarts model is still used to model and analyze fertility and fertility changes (Stover, 1998). We use the revised model to look at trends in these proximate determinants and concomitant trends in fertility levels. Johnson and colleagues found that the model was useful and efficient in understanding the contributions of the proximate determinants on fertility levels in 13 countries in SSA, including Kenya (Johnson et al., 20II). The model showed that marriage and contraceptive use were the determinants that had the greatest impact on reducing fertility in these countries.

\section{Methods}

Study Area and Population

Data for this paper come from the Nairobi CrossSectional Slum Surveys (NCSS) that the African Population and Health Research Center (APHRC) designed and implemented in 2000 and 2012 in all Nairobi's informal settlements. These surveys constitute part of strategies to improve the living conditions of the urban poor through evidence-based programs and actions. The first survey was conducted in 2000 (2000 NCSS) to examine population and health problems that the residents of Nairobi's informal settlements faced, with the aim to compare these indicators with those of other population sub-groups based on national surveys. In 2012 , a second survey (20I2 NCSS) was conducted to document changes (if there were any) since 2000 in the socio-economic and health outcomes of these residents, including fertility regulation, levels and trends. Given the substantial investments in the social and health sectors by the Kenya Government and its development partners, it was anticipated that the 2012 NCSS would provide evidence on the progress made towards achieving the Millennium Development Goals (MDGs) 4, 5 and 7 in the country, as well as changes in the social, demographic and health profiles of residents of Nairobi's informal settlements since 2000 (APHRC, 20I4). The 2000 NCSS was conducted among a random probability sample of 3,256 women aged 15-49 while the 2012 NCSS involved 4,240 women aged I2-49. This paper focuses on women of reproductive age (15-49 years old), that is, 3,256 women in 2000 and 3,892 women in 2012 .

\section{Statistical approach}

All analyses were performed using Stata 13 (Stata Corporation, 2013).

We use descriptive statistics (frequencies, medians) to look at changes in the onset of first marriage, timing of first sexual experience, contraceptive prevalence and durations of postpartum amenorrhea, abstinence and insusceptibility in conjunction with changes in total fertility rates (TFRs) over the inter-survey period. We also compare these women to 8,444 women aged 15-49 years from the 2008-2009 KDHS.

\section{Outcome Measures}

\section{Onset of First Marriage}

Women were asked how old they were at their first marriage. We calculate the median age at first marriage among women aged I5-49 years as well as the proportion of women who were first married by age 18 among women aged 15-24 years, 25-39 years and $40-49$ years.

\section{Timing of First Sexual Experience}

Women were asked how old they were at the first sexual contact. We calculate the median age at first coitus for women aged 25-49 years due to the sparse data among younger women, regarding sexual activity.

\section{Contraceptive Prevalence}

Women were asked about whether they were currently using anything to prevent conception and 
what method they were using. We classify these methods into modern methods and traditional methods and calculate the proportion of currently married women aged 15-49 years who were using a method by type of method used. Modern methods include pill, intrauterine device (IUD), injections, implants, diaphragm, foam, jelly, male and female condoms, male and female sterilization and lactational amenorrhea (LAM). Traditional methods include periodic abstinence (rhythm), withdrawal and abstinence.

\section{Post-partum Amenorrhea, Abstinence, and Insusceptibility}

The duration of post-partum insusceptibility is taken as the longer duration of either amenorrhea or abstinence. Women who had given birth in the three years preceding the surveys were asked about the duration of amenorrhea and sexual abstinence since the birth of their last child. We calculate the median duration of post-partum amenorrhea, abstinence and insusceptibility in months.

\section{Total Fertility Rate}

The total fertility rate is defined as the average number of children a woman would be expected to have by the end of her childbearing years if current age-specific fertility rates did not change until all the women who were being observed had attained 49 years. Forty-nine is assumed to be the age at which most women complete childbearing (APHRC, 2002). Women were asked about the children they had given birth to up to the day of the survey and the TFRs are calculated for the 3 years preceding the survey for women aged 15-49.

\section{Computing the Indices}

We also look at Bongaarts' proximate determinants of fertility framework to compare women in Nairobi's informal settlements in 2000 to similar women in 2012 and in 2008-2009 KDHS. We use four indices as detailed below. For each of the indices, the lower the value, the greater its contribution to reduction in potential fertility.

\section{The Index of Insusceptibility $\left(C_{i}\right)$}

Post-partum insusceptibility approximates the combined fertility-inhibiting effects of post-partum amenorrhea and post-partum abstinence. The index is calculated as the average birth interval in the absence of breastfeeding divided by the average length in the presence of breastfeeding. The equation is expressed as (Bongaarts and Potter, 1983, UNFPA, 2014, Stover, 1998):

$\mathrm{C}_{\mathrm{i}}=20 /(18.5+\mathrm{PPI})$, where,
- 20 months $=w$ months $+x$ months $+y$ months $+z$ months and is an average of minimum length of the period between one birth and conception of the next birth in the absence of breastfeeding

$0 \quad \mathbf{w}=1.5$ months is the minimum post-partum infecundable period

○ $\mathbf{x}=7.5$ months is the average waiting time to conception

$\circ y=2$ months is the average waiting time contributed by spontaneous abortion

- $\quad z=9$ months is the average length of a fullterm pregnancy

- $\quad 18.5$ months $=x$ months $+y$ months $+z$ months

- $\mathrm{PPI}=$ Median duration of post-partum insusceptibility (in months) that is caused by breastfeeding and post-partum abstinence

\section{The Index of Marriage $\left(C_{m}\right)$}

This is often approximated as the proportion of women of reproductive age in union (ranges from 0 to I) as this marks the exposure to sexual intercourse. However, as the importance of marriage as a reliable indicator of the beginning of sexual activity is decreasing, the reliability of sexual history data is increasing. It would therefore be more appropriate to approximate $\mathrm{C}_{\mathrm{m}}$ as the proportion of women that are sexually active as revised by Stover (UNFPA, 2014, Stover, 1998). This revised index of marriage was calculated for women in both 2000 and 2012 NCSS surveys and 2008-2009 KDHS data was used to calculate the same for women in Nairobi, rural Kenya and Kenya as a whole. Thus:

- $\mathrm{C}_{\mathrm{m}}=$ Proportion of women of reproductive age that are sexually active in the last 4 weeks preceding the survey

\section{The Index of Contraception $\left(C_{c}\right)$}

This index describes the effect of contraceptive use on fertility levels. The equation is expressed as:

$\mathrm{C}_{\mathrm{c}}=\mathrm{I}-\left(\mathrm{I} .08 *\right.$ Prevalence* ${ }^{*}$ Effectiveness $)$, where,

- $\quad 1.08=A$ sterility correction factor for those couples who do not use family planning because they either know or believe that they are infecund (UNFPA, 20I4)

- Effectiveness=The weighted average of the effectiveness of contraception in a population, where the weights are equal to the prevalence of a given method (Futures Group, 1997)

- $\quad$ Prevalence $=$ The contraceptive prevalence among married women. However, we take into account the contraceptive prevalence among sexually active, fecund women (Stover, 1998), because sexual activity as a marker for exposure to pregnancy becomes more important. 


\section{The Index of Sterility $\left(C_{s}\right)$}

This index assesses the contribution of both primary and secondary sterility in lowering prevailing fertility levels. The original equation by Bongaarts (Bongaarts et al., 1984) was developed to estimate this index because data on sterility were scarce. However, it is possible to calculate the proportion of infecund women from most recent survey data and Stover (1998) devised a new calculation of this index as $C_{s}=I-f$, where:

- $f=$ proportion of sexually active women who are infecund

However, despite the fact that sexual activity in the preceding 4 weeks was under reported in the 2000 NCSS survey, we can still determine the proportion of the sexually active women that are infecund.

Total Fertility Rate (TFR) Approximation using Bongaarts's Aggregate Model

TFR can be approximated using the combined indices in the Bongaarts's framework, that is the index of insusceptibility, the index of contraception, the index of marriage, the index of sterility and the index of abortion to estimate their contribution to the prevailing fertility rates. Bongaarts' (Bongaarts et al., 1984) original model is TFR $=T F * C_{m}{ }^{*} C_{i}{ }^{*} C_{c}{ }^{*} C_{s}{ }^{*} C_{a}$, where:

- $T F=$ Total fecundity is the prevailing total fertility rate in the absence of all the fertility inhibitors and is approximately 15.3 births per woman
However, Stover revised the model (Stover, 1998) so that it became TFR $=\mathrm{PF}^{*} \mathrm{C}_{\mathrm{m}}{ }^{*} \mathrm{C}_{\mathrm{i}}{ }^{*} \mathrm{C}_{\mathrm{c}}{ }^{*} \mathrm{C}_{\mathrm{s}}{ }^{*} \mathrm{C}_{\mathrm{a}}$, where:

- $\quad P F=$ Potential fertility, that is, the prevailing total fertility rate in a population of women that are sexually active, fecund from age 15-49 years, who did not practice breastfeeding, experience post-partum abstinence or use contraceptives. This is 21 births per woman.

In this paper, we use the model without the index of abortion, as this information is very limited in the surveys. The model enable us to determine the changes in efficacy of each proximate determinant between 2000 and 2012 and to determine the most important of these determinants in reducing potential fertility.

\section{Results}

\section{Total Fertility Rate}

Figure I compares the TFR among women aged I549 years from the 2012 NCSS, the 2000 NCSS and the 2008-2009 KDHS surveys. In 20I2, TFR among women in the slums was 3.5 children per woman, which was lower than in the whole of Kenya (4.6) and rural Kenya (5.2) in 2008-2009. It declined from 4.0 in Nairobi's slums in 2000. However, it remained higher than the TFR among similar non-slum Nairobi women (2.8).

Figure 1

Total Fertility Rates,

NCSS 2000 \& 2012 and KDHS 2008-09

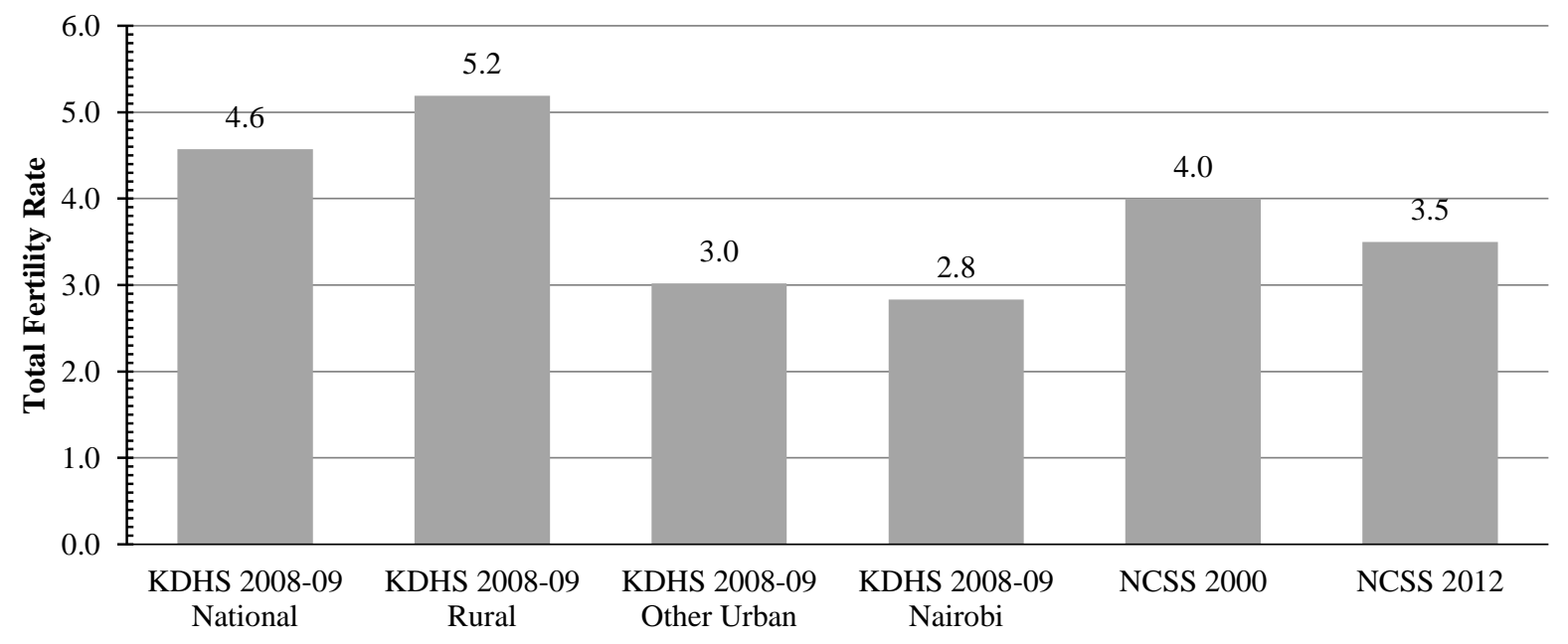

- Total fertility rate (TFR) (15-49) 
Bongaarts' proximate determinants of fertility

\section{framework}

Figure 2 summarizes the index of insusceptibility, the index of contraception, the index of marriage and the index of sterility for Nairobi's informal settlements in 2012 and 2000 and for Kenya as a whole, rural Kenya and Nairobi in 2008-09.

\section{A. The Index of Sterility $\left(C_{s}\right)$}

Sterility was the least powerful fertility-inhibiting proximate determinant in the three areas. The effect of sterility was most powerful nationally and in rural areas of Kenya in 2008-09 and in Nairobi's slums in 2000 (0.96) and its effect was lowest in Nairobi in 2008-09 (0.99). The index of sterility in Nairobi's slums was 0.98 in 2012, indicating that it played a slightly greater role in reducing fertility in these settings in that year than in other parts of Nairobi in 2008-2009. This proximate determinant was more effective in reducing fertility in Nairobi's slums in 2000 and in 2012 (0.96 and 0.98, respectively).

\section{$B$. The Index of Insusceptibility $\left(C_{i}\right)$}

The greatest effect of post-partum insusceptibility was observed in rural Kenya in 2008-09 (0.67), while the index was least effective in Nairobi's slums in 2012 (0.9I). Between 2000 and 20I2, the index of insusceptibility increased from 0.87 to 0.91 , indicating that its contribution as a fertility-inhibitor in Nairobi's slums had decreased. It was higher in 2012 than in Nairobi in 2008-09 (0.84). The increasing index indicates a decrease in the durations of post-partum abstinence and breastfeeding in Nairobi's slums. It also suggests that these durations were shorter among women in Nairobi slums in 2012 than in other non-slum parts of Nairobi in 2008-09

\section{The Index of Marriage $\left(C_{m}\right)$}

The index of marriage as measured by recent sexual activity had not changed much over time in Nairobi slums, going from 0.62 in 2000 to 0.57 in 2012. This suggest that the effect is lower compared to the whole of Nairobi (0.47), rural Kenya (0.48) and other parts of Kenya in 2008-09 (0.49).

\section{$D$. The Index of Contraception $\left(C_{c}\right)$}

Contraceptive use was the most powerful fertilityinhibiting proximate determinant in 20I2. It became much more efficient at inhibiting fertility in Nairobi's informal settlements in the inter-survey period as the index decreased significantly from 0.63 in 2000 to 0.39 in 2012. It was lower than the index of contraception among women in non-slum parts of Nairobi in 2008-09 (0.4I). The index was less effective in rural Kenya than in Kenya as whole in 2008-09 (0.52 versus 0.50 , respectively). 


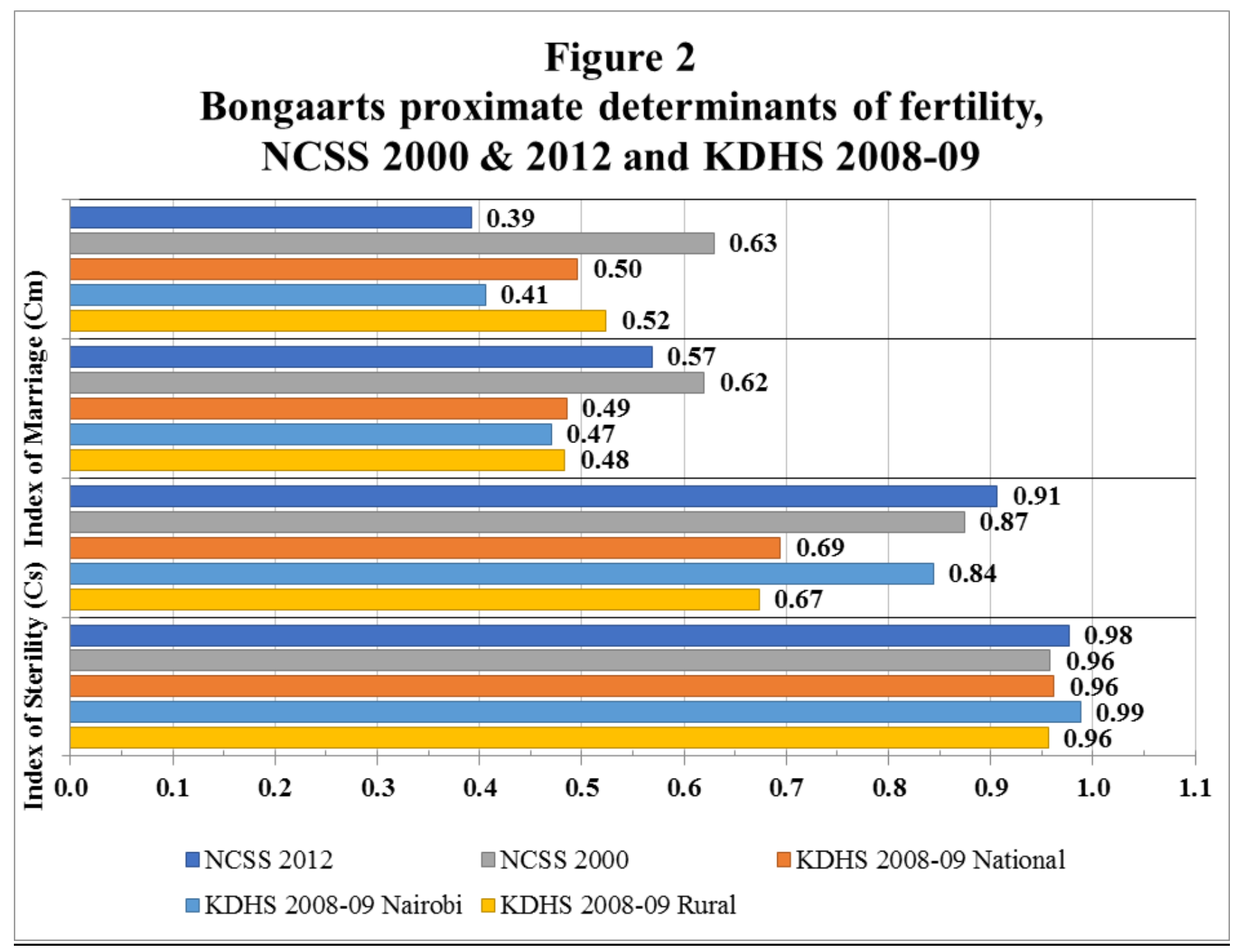

Effect of Contraceptive Use on Fertility Levels

Table I shows that Bongaarts's framework produced TFRs that were different from the direct estimates, particularly in the 2000 NCSS survey where the estimate produced by Bongaarts's framework was greater than the direct estimate by 2.9 children per woman. The smallest difference in TFRs calculated directly and estimated by the Bongaarts' framework was observed in the whole of Nairobi in 2008-2009 where the two TFRs differed by 0.5 births, followed by Nairobi's slums in 2012 where the difference between the two TFRs was 0.6 births. In both rural and the whole of Kenya in 2008-2009, the framework gave a TFR that was 1.8 births and 1.2 births lower, respectively.

The effect of contraception on fertility levels was most pronounced in Nairobi's slums, where contraceptive use reduced fertility by 6.4 births in 2012, compared to a reduction of 4.0 births in 2000 . In 2008-2009, contraception reduced fertility by 4.9 births in non-slum parts of Nairobi, 3.I births in rural Kenya and 3.4 births in the whole of Kenya. 
Table I: Bongaarts Proximate Determinants of Fertility

Index of insusceptibility, Index of Contraception, Index of Marriage, Index of Sterility, Total fertility rates using Bongaarts framework and Effect of contraception on total fertility rate, NCSS 2012, NCSS 2000 and KDHS 2008-09

\begin{tabular}{|c|c|c|c|c|c|c|c|c|c|}
\hline \multirow[b]{2}{*}{ Survey } & \multicolumn{4}{|l|}{ Indices } & \multicolumn{3}{|c|}{ Total fertility rate (TFR) } & \multicolumn{2}{|c|}{$\begin{array}{l}\text { Effect of contraception on } \\
\text { total fertility rate }\end{array}$} \\
\hline & $\begin{array}{l}\text { Index of } \\
\text { Insuscep- } \\
\text { tibility }\left(C_{i}\right)\end{array}$ & $\begin{array}{l}\text { Index of } \\
\text { Contra- } \\
\text { ception } \\
\left(C_{c}\right)\end{array}$ & $\begin{array}{l}\text { Index of } \\
\text { Marriage } \\
\left(C_{m}\right)\end{array}$ & $\begin{array}{l}\text { Index of } \\
\text { Sterility } \\
\left(C_{s}\right)\end{array}$ & $\begin{array}{l}\text { TFR (Using } \\
\text { Bongaarts } \\
\text { framework) }\end{array}$ & $\begin{array}{l}\text { TFR (Direct } \\
\text { estimate) }\end{array}$ & $\begin{array}{l}\text { Differ- } \\
\text { ence }\end{array}$ & $\begin{array}{l}\text { TFR (Using } \\
\text { Bongaarts } \\
\text { framework) } \\
\left.\text { (Without } C_{c}\right)\end{array}$ & $\begin{array}{l}\text { Number of } \\
\text { births by } \\
\text { which } \\
\text { fertility is } \\
\text { reduced }\end{array}$ \\
\hline NCSS 2012 & 0.91 & 0.39 & 0.57 & 0.98 & 4.1 & 3.5 & 0.6 & 10.6 & 6.4 \\
\hline $\begin{array}{l}\text { KDHS } \\
\text { 2008-09 }\end{array}$ & & & & & & & & & \\
\hline Nairobi & 0.84 & 0.41 & 0.47 & 0.99 & 3.3 & 2.8 & 0.5 & 8.2 & 4.9 \\
\hline Rural & 0.67 & 0.52 & 0.48 & 0.96 & 3.4 & 5.2 & -1.8 & 6.5 & 3.1 \\
\hline National & 0.69 & 0.50 & 0.49 & 0.96 & 3.4 & 4.6 & -1.2 & 6.8 & 3.4 \\
\hline
\end{tabular}

Source: Nairobi Cross-Sectional Slum Surveys (NCSS) 2000 \& 2012, Kenya Demographic and Health Surveys (KDHS) 2008-09 
Figure 3 summarizes contraceptive prevalence among women who were currently married and aged 15-49 years at the time of the survey. The proportion of women in Nairobi slums using traditional methods decreased from 7 percent in 2000 to 4 percent in 2012. The lowest prevalence of traditional methods was observed in the Nairobi slums in 2012 (4 percent) compared with other parts of Kenya in 2008-2009. Over half of currently married women in 2012 were using any modern method (54 percent) compared to 39 percent in 2000 . The proportion using modern methods in 2012 was higher than that of similar groups of women from non-slum areas of Nairobi in 2008-2009 (49 percent). The lowest modern contraceptive prevalence was observed in rural Kenya in 2008-2009 where only 37 percent of currently married women reported using such methods. The patterns of use of any method were similar to those of modern methods. The proportion using any method was highest among women in Nairobi's slums in 2012 (57 percent), which represented an increase from 46 percent in 2000. Use of any method was lowest among women in rural areas (43 percent).

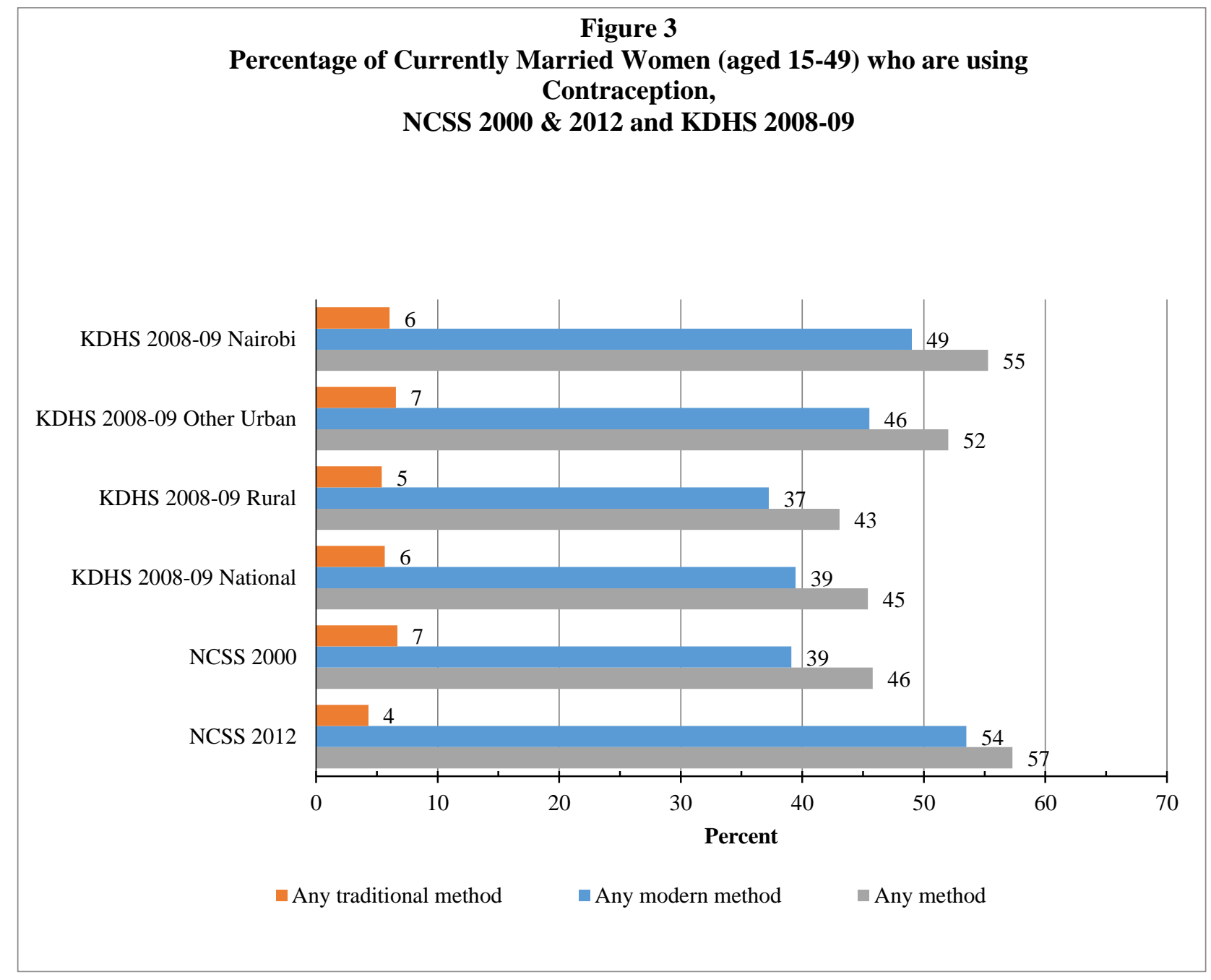

Effect of Marriage and Sexual Activity on Fertility Levels

There was postponement of onset of marriage in Nairobi's slums between 2000 and 2012 with fewer older women being married by the age of 18 years. Figure 4 shows that among those aged $40-49$ years the proportion married by age 18 decreased from 46 percent to 31 percent, while for those aged 25-39 years it decreased from 28 percent to 25 percent. The proportion did not change among young women aged I5-24 years ( 22 percent). 


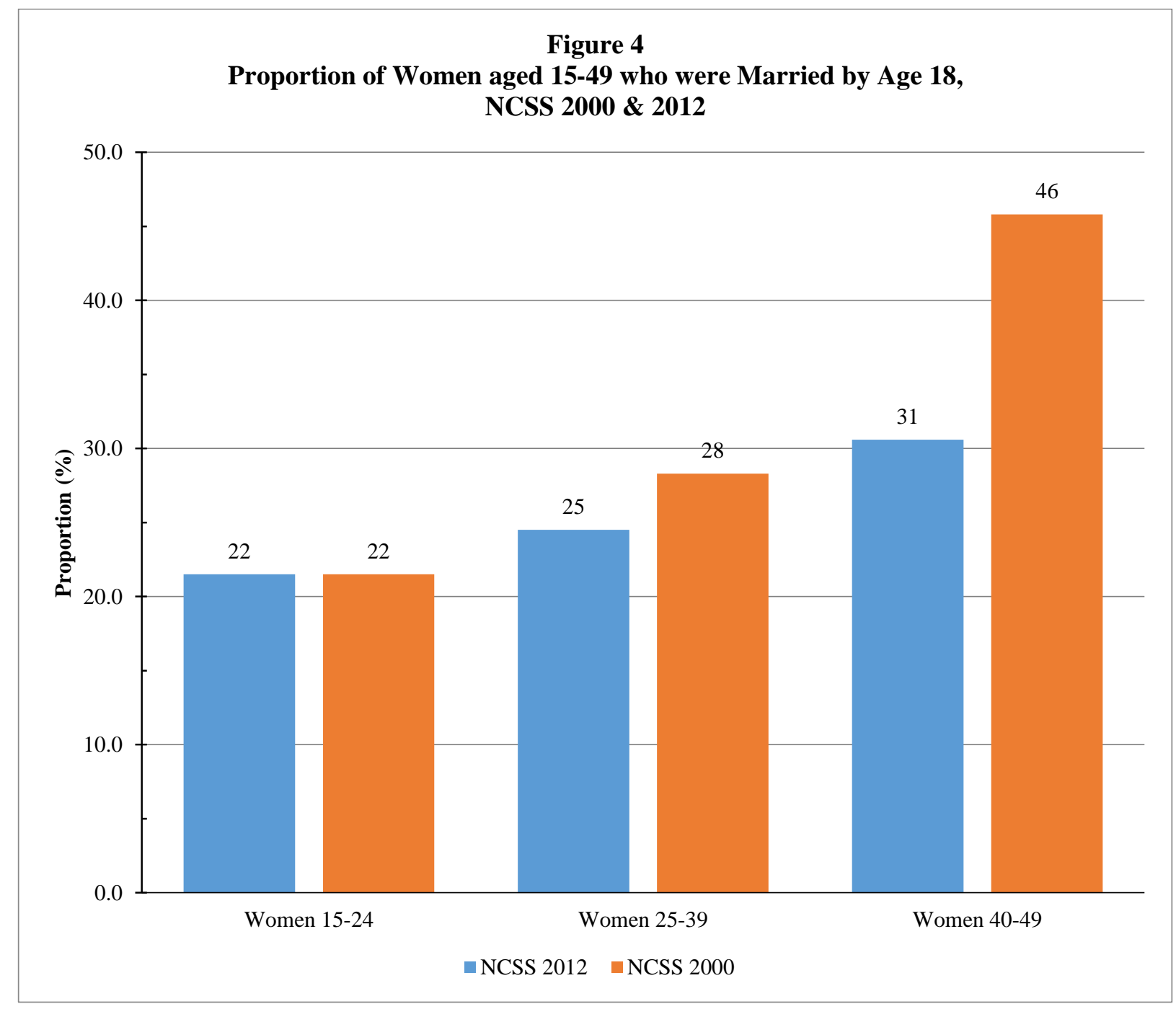

Figure 5 shows that the median age at first sex among slum residents increased from 16.7 years in 2000 to 19.0 years in 2012 among women aged $25-49$ years. This was still one year earlier than non-slum Nairobi women who initiated sex at about 20 years of age. In terms of marriage, there was a delay of about 2 years among women aged 15-49 years in Nairobi's slums in 2012 compared to similar women in 2000 . Women in Nairobi's slums in 2012 married at about 22 years of age but this was still earlier than their non-slum counterparts who married at about 24.2 years old. 


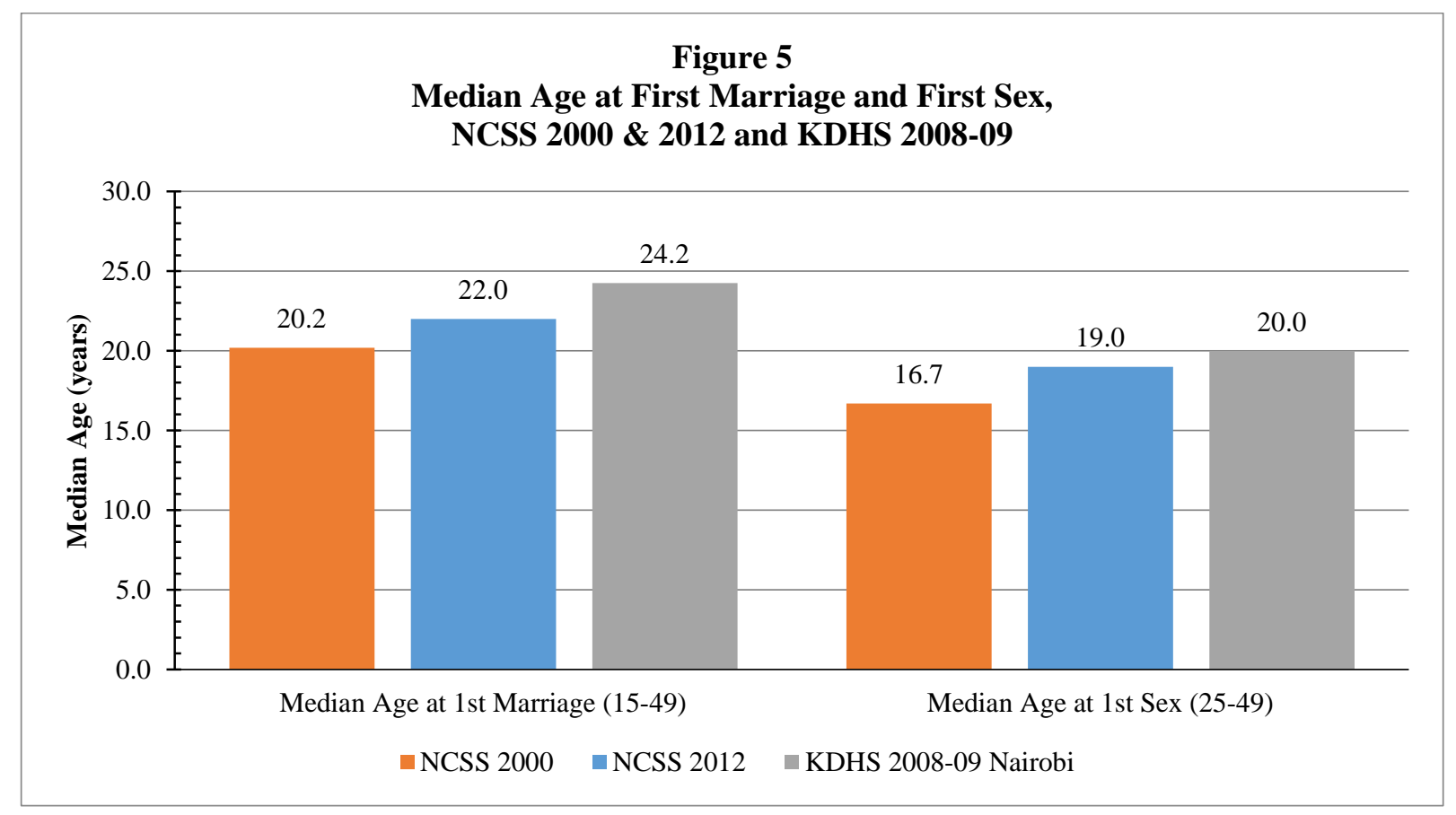

Effect of Post-Partum Amenorrhea, Abstinence and Insusceptibility on Fertility Levels

Figure 6 shows that women in Nairobi's slums in 2000 were insusceptible to conception for a much longer duration (8.5 months) compared with their counterparts in 2012, who were insusceptible for only 3.6 months. Women in non-slum Nairobi in 2008-09 were insusceptible for a longer duration (5.2 months) compared to women in Nairobi's informal settlements in 20/2. However, the longest insusceptibility to conception was observed among rural women in 2008-09 whose median duration of post-partum insusceptibility was 11.2 months. The durations of post-partum insusceptibility are affected by patterns of post-partum abstinence and amenorrhea, with the duration of amenorrhea contributing the most to insusceptibility.

Among women aged 15-49 years in Nairobi's slums, the median duration of post-partum abstinence increased very slightly from 2.6 months in 2000 to 2.7 months in 2012 whereas the median duration of post-partum amenorrhea decreased by about 4 months from 7.2 months in 2000 to 3.0 months in 2012. A comparison of slum women in 2012 with their non-slum Nairobi women in 2008-09 showed that post-partum abstinence was slightly shorter (2.5 months) while post-partum amenorrhea was slightly longer (4.3 months) among non-slum residents. Women in rural Kenya in 2008-09 abstained for 3.2 months on average, which was a slightly longer duration than that observed among women in Nairobi's slums in 2012 (2.7 months). The duration of post-partum amenorrhea among women in rural Kenya in 2008-09 was longer at 9.7 months compared to only 3.2 months among similar women in Nairobi's slums in 2012. 


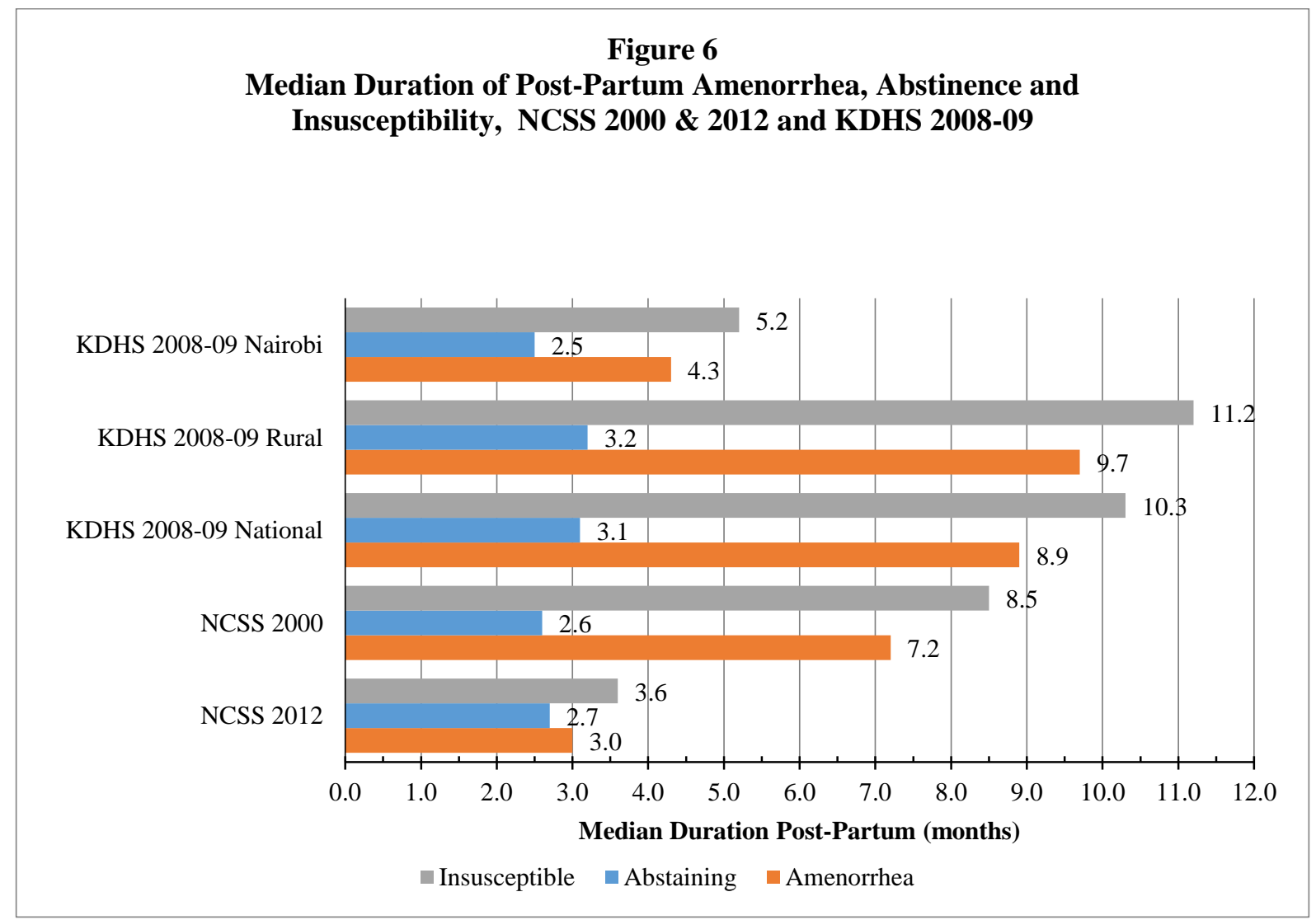

\section{Discussion and Conclusion}

There is very little evidence about fertility patterns and determinants among the urban poor in subSaharan Africa. This paper contributes to filling this evidence gap by examining the role of proximate determinants in influencing fertility patterns among women living in slums in Nairobi, Kenya using unique DHS-type data collected in all Nairobi slums between 2000 and 2012.

First, fertility declined in the slums in the intersurvey period but was still higher in slums in 2012 than in Nairobi in 2008-09. This indicates that while fertility rates might be stalling among women in SSA (Bongaarts, 2008), women in Nairobi slums are consistently experiencing higher fertility. This is consistent with other studies that found that even within Kenya, there were differences in the decline of fertility rates among women from different subgroups (Ezeh et al., 2009).

The findings show that there has been a change in the influence of proximate determinants on fertility among women living in slum settlements. Marriage as measured by recent sexual activity had the largest inhibiting effect followed closely by contraception in 2000 , whereas in 2012 contraception had the largest fertility inhibiting effect followed by marriage. To note, the contraception inhibiting effect was much larger than that of marriage effect in 2012 while there was not much difference between the two determinants in 2000. This suggests that in 2012, fertility reductions from the biological maximum were mostly brought about by contraceptive use in these poor urban settings in 2012. Evidence suggest that family planning programs may be increasingly reaching the urban poor, with the poor-rich gap in the use of modern contraception in urban Kenya dwindling over time (Fotso et al., 2013). The proportion of married women using any modern method of contraception increased from $39 \%$ to $54 \%$ between 2000 and 2012. Index of contraception was more effective in inhibiting fertility in Nairobi slums in 2012 than in non-slum Nairobi in 2008-09. Given the role played by contraception, efforts aimed at further increasing contraceptive use should be maintained, especially to meet the needs of women who have unmet need for family planning in these urban poor settings (15\% for spacing and $8 \%$ for limiting in 20/2).

Marriage as measured by recent sexual activity became slightly more effective as a fertility-inhibitor in the slums in the inter-survey period, which is consistent with the delay in sexual debut between 2000 and 2012. This could be also linked to the increased use of contraception by married and sexually active unmarried women. Data show that modern contraceptive use increased from $58 \%$ in 2000 to $67 \%$ in 2012 among sexually active unmarried women. Marriage was however more effective in Nairobi, rural Kenya and other parts of Kenya in 2008-09. 
Postpartum insusceptibility is the third fertility inhibitor after contraception and marriage and it even became less effective as a fertility-inhibitor in the slums between 2000 and 20I2. It was more effective in Nairobi in 2008-09 than in slums in 2012. Duration of amenorrhea, an important factor in postpartum insusceptibility decreased significantly in the slums between 2000 and 2012. Since the extent and duration of breastfeeding affect postpartum insusceptibility (Short, 1993), the finding suggests that the duration of breastfeeding may have decreased over time. This could be attributed to the desire to replace children who die by having short birth intervals given the high infant and child mortality in the slums (Doskoch, 2010, APHRC, 2014). More importantly, recent evidence suggest poor adherence to World Health Organization (WHO) recommendations in terms of breastfeeding and infant nutrition practices in slum settings. Data show that only about $2 \%$ of infants born between 2006 and 2010 were exclusively breastfed for six months (Kimani-Murage et al., 20l I). Given the important role that postpartum infecundity plays in inhibiting fertility, there is need to promote breastfeeding for longer periods among these urban poor women. Because of the limited access to basic public services in these settings, women often deliver at home or at private health facilities, with little possibility of getting information on optimal breastfeeding that are often provided through government initiatives (KimaniMurage et al., 201 I, Fotso et al., 2009). Targeted initiatives such as home-based counselling of mothers for infant feeding and/or strengthening the capacity of private health providers to offer services on breastfeeding may be critical for these urban poor women. The role of lactational amenorrhea as form of contraception could be more emphasized during such initiatives.

It is worth noting a few limitations of this paper. First, we did not include index of abortion in the analysis due to lack of appropriate data. We did not capture the important role that men play in shaping fertility patterns in SSA. Also, the comparison with 2008-2009 KDHS may be misleading given the difference between the periods when the surveys were conducted. Despite these limitations, this paper offers unique perspective on the determinants of fertility among slum populations who constitute an increasing share of urban populations in Kenya and SSA in general. Although TFR in Nairobi's informal settlements declined over time, there still remained disparities between women in the slums and those from other parts of the County. The findings suggest the need to sustain and/or strengthen reproductive health initiatives that emphasize contraceptive use especially among women in urban slums in Kenya.
This should be an important part of managing the growth of slums in developing countries such as Kenya.

\section{References}

AGBOLA, T. \& AGUNBIADE, E. M. 2009. Urbanization, Slum Development and Security of Tenure: The Challenges of Meeting Millennium Development Goal 7 in Metropolitan Lagos, Nigeria. In: DE SHERBININ, A., RAHMAN, A., BARBIERI, A., FOTSO, J. C. \& ZHU, Y. (eds.) Urban Population-Environment Dynamics in the Developing World: Case Studies and Lessons Learned. Paris: Committee for International Cooperation in National Research in Demography (CICRED).

APHRC 2002. Population and Health Dynamics in Nairobi's Informal Settlements. Nairobi: African Population and Health Research Center,.

APHRC 2014. Population and Health Dynamics in Nairobi's Informal Settlements: Report of the Nairobi Cross-sectional Slums Survey (NCSS) 2012. Nairobi: African Population and Health Research Center,.

BASCHIERI, A. \& HINDE, A. 2007. The proximate determinants of fertility and birth intervals in Egypt: An application of calendar data. Demographic Research, 16, 59-96.

BONGAARTS, J. 2008. Fertility Transitions in Developing Countries: Progress or Stagnation? Studies in Family Planning, 39, I05-I I 0.

BONGAARTS, J., FRANK, O. \& LESTHAEGHE, R. 1984. The Proximate Determinants of Fertility in Sub-Saharan Africa. Population and Development Review, 10, 5I I-537.

BONGAARTS, J. \& POTTER, R. G. 1983. Fertility, Biology, and Behavior: An Analysis of the Proximate Determinants, New York, Academic Press.

BREMNER, J., HAUB, C., LEE, M., MATHER, M. \& ZUEHLKE, E. 2009. World Population Highlights: Key Findings from PRB's 2009 World Population Data Sheet. Population Bulletin, Vol 64, No 3. Population Reference Bureau.

$\mathrm{CHAN}, \mathrm{M}$. Urban health threatened by inequities. World Health Day 2010: Urban health matters, 2010 Geneva, Switzerland.

CHEN, N., VALENTE, P. \& ZLOTNIK, H. 1998. What do we know about recent trends in urbanization? In: BILSBORROW, R. E. (ed.) Migration, urbanization, and development: new directions and issues. New York, New York: United Nations Population Fund.

DOSKOCH, P. 2010. Why Is Kenya's Fertility Rate Still High? HIV Epidemic May Be a Factor. 
International Perspectives on Sexual and Reproductive Health, 36, 2II-2I 2.

EZEH, A., KODZI, I. \& EMINA, J. 20I0. Reaching the Urban Poor with Family Planning Services. Studies in Family Planning, 4I, I09-II6.

EZEH, A., MBERU, B. U. \& EMINA, J. 2009. Stall in fertility decline in Eastern African countries: regional analysis of patterns, determinants and implications. Philosophical Transactions of the Royal Society B Biological Sciences, 364, 29913007.

FOTSO, J., EZEH, A., MADISE, N., ZIRABA, A. \& OGOLLAH, R. 2009. What does access to maternal care mean among the urban poor? Factors associated with use of appropriate maternal health services in the slum settlements of Nairobi, Kenya. Maternal and Child Health Journal, I3, I30 - I37.

FOTSO, J. C., SPEIZER, I., MUKIIRA, C., KIZITO, P. \& LUMUMBA, V. 20I3. Closing the poor-rich gap in contraceptive use in urban Kenya: are family planning programs increasingly reaching the urban poor? International Journal for Equity in Health, 12, 7|.

FUTURES GROUP. 1997. Proximate Determinants of Fertility [Online]. Available: http://futuresgroup.com/resources/software mod els/proximate determinants of fertility [Accessed February 2 Ist 20I4].

GAGE, A. J. \& MEEKERS, D. 1994. Sexual activity before marriage in sub-Saharan Africa. Biodemography and Social Biology, 4I , 44-60.

JOHNSON, K., ABDERRAHIM, N. \& RUTSTEIN, S. O. 20II. Changes in the Direct and Indirect Determinants of Fertility in Sub-Saharan Africa. DHS Analytical Studies No. 23. Calverton, Maryland, USA: ICF Macro.

KESSIDES, C. 2005. The Urban Transition in SubSaharan Africa: Implications for Economic Growth and Poverty Reduction World Bank.

KIMANI-MURAGE, E., MADISE, N., FOTSO, J. C., KYOBUTUNGI, C., MUTUA, M., GITAU, T. \& YATICH, N. 20I I. Patterns and determinants of breastfeeding and complementary feeding practices in urban informal settlements, Nairobi Kenya. BMC Public Health, 396.
KYOBUTUNGI, C., ZIRABA, A. K., EZEH, A. \& YÉ, Y. 2008. The burden of disease profile of residents of Nairobi's slums: Results from a Demographic Surveillance System. Population Health Metrics, 6.

ROSSIER, C., SENDEROWICZ, L. \& SOURA, A. 2014. Conflicted fertility preferences among the urban poor in Ouagadougou, Burkina Faso Population Association of America (PAA). Boston, Massachussets, USA.

SHORT, R. V. 1993. Lactational infertility in family planning. Annals of Medicine, 25, I75- I80.

STATA CORPORATION 2013. Stata: Release 13. Statistical Software, College Station, TX StataCorp LP.

STOVER, J. 1998. Revising the Proximate Determinants of Fertility Framework: What Have We Learned in the past 20 Years? Studies in Family Planning, 29, 255-267.

UN-HABITAT 2003a. The challenge of slums: Global Report on Human Settlement 2003. United Nations Human Settlements Programme.

UN-HABITAT 2003b. Guide to Monitoring Target II: Improving the lives of 100 million slum dwellers. Nairobi: United Nations Human Settlements Programme, .

UN-HABITAT 2003c. Slums of the World: The face of urban poverty in the millennium? Nairobi: United Nations Human Settlements Programme, .

UN 2004. World Urbanization Prospects: The 2003 Revision. New York: United Nations.

UN 2009. World Urbanization Prospects: The 2008 Revision. New York: United Nations.

UN 2013. World Fertility Report: 2012. New York, USA: United Nations, Department of Economic and Social Affairs Population Divison, .

UNFPA. 2014. Population Analysis for Policies \& Programmes (PAPP) 101: Introduction to Demographic Analysis, Session 05: Proximate determinants of fertility [Online]. United Nations Population Fund, . Available: http://papp.iussp.org/sessions/papp I0 I s05/PAPP 101 s05 010 010.html [Accessed February 21st 20|4].

ZULU, E. M., DODOO, F. N.-A. \& EZEH, A. 2002. Sexual Risk-Taking in the Slums of Nairobi, Kenya, 1993-98. Population Studies, 56, 3 I I-23. 